\title{
Animal Models of Ischemic Stroke. Part One: Modeling Risk Factors
}

\author{
Marco Bacigaluppi ${ }^{1-3}$, Giancarlo Comi ${ }^{3}$ and Dirk M. Hermann*,1,4
}

\author{
${ }^{I}$ Department of Neurology, University Hospital Zurich (USZ), Zurich, Switzerland; ${ }^{2}$ Neuroimmunology Unit, DIBIT and \\ ${ }^{3}$ Institute of Experimental Neurology (INSPE), IRCCS San Raffaele Hospital, Milan, Italy; ${ }^{4}$ Department of Vascular \\ Neurology, Dementia and Ageing Research, Neurology Clinic, University Hospital Essen, Essen, Germany
}

\begin{abstract}
Ischemic stroke is one of the leading causes of long-term disability and death in developed and developing countries. As emerging disease, stroke related mortality and morbidity is going to step up in the next decades. This is both due to the poor identification of risk factors and persistence of unhealthy habits, as well as to the aging of the population. To counteract the estimated increase in stroke incidence, it is of primary importance to identify risk factors, study their effects, to promote primary and secondary prevention, and to extend the therapeutic repertoire that is currently limited to the very first hours after stroke. While epidemiologic studies in the human population are essential to identify emerging risk factors, adequate animal models represent a fundamental tool to dissect stroke risk factors to their molecular mechanism and to find efficacious therapeutic strategies for this complex multi- factorial disorder. The present review is organized into two parts: the first part deals with the animal models that have been developed to study stroke and its related risk factors and the second part analyzes the specific stroke models. These models represent an indispensable tool to investigate the mechanisms of cerebral injury and to develop novel therapies.
\end{abstract}

Keywords: Aging, animal model, atherosclerosis, hypercholesterolemia, hyperhomocysteinemia, hypertension, ischemic stroke, risk factor.

\section{INTRODUCTION}

Stroke represents the leading cause of long-term disability and second-frequent cause of mortality among all causes of death (behind cardiovascular diseases (CVD)) (National Center for Health Statistics, http://www.cdc.gov/nchs/fastats/ deaths.htm) [1]. Among noninstitutionalized U.S. adults the estimated prevalence of stroke in 2005 was 2.6\%, approximately $5,839,000$ persons, being similar among men $(2.7 \%)$ and women $(2.5 \%)$. It is expected that these numbers will dramatically step up in the next years and to increase by almost one half by 2020. This is due to the increase in the mean population age, the persistence and the increase of unhealthy life habits, including physical inactivity, tobacco smoking, excessive and unhealthy food resulting in obesity, arterial hypertension, hypercholesterolemia and type II diabetes affecting in particular young patients, in both industrialized and developing countries [2] [World Health Organization, http://www.who.int/cardiovascular_diseases/resources/ atlas/en]. The incidence and prevalence of ischemic stroke, together with its long-term consequences account for an estimated direct and indirect cost of $\$ 65.5$ billion in 2008 , reflecting a mean lifetime cost of a stroke patient of $\$ 140,048$ (estimation for the United States) that includes inpatient care, rehabilitation and follow-up care [3].

Ischemic stroke accounts for approximately $87 \%$ of all strokes $(10 \%$ are intracerebral hemorrhages, and $3 \%$ are subarachnoid hemorrhages) (National Institute of Neurological Disorders and Stroke), resulting from embolic or throm-

*Address correspondence to this author at the Department of Vascular Neurology, Dementia and Ageing Research, Neurology Clinic, University Hospital Essen, Hufelandstr. 55, D-45122 Essen, Germany; Tel: +49-201-723 2180; Fax: +49-201-723-5534; E-mail: dirk.hermann@uk-essen.de botic occlusion of a major cerebral artery, most often the middle cerebral artery (MCA) or one of its branches.

Stroke is a complex disorder precipitated by a variety of genetic and environmental factors. The clinical variability of stroke, mainly in terms of duration, localization and severity of ischemia, as well as the patients' age and coexisting systemic diseases, poses huge challenges for clinical research, as very large patient groups are needed to avoid the confounding effects of disease diversity. Although experimental longitudinal clinical studies are of major importance for understanding stroke, having provided strong evidence for the existence of genetic and environmental influence factors, they are seldom helpful in understanding disease mechanisms and their results can be misleading [4]. On the other hand, in vitro systems alone cannot thoroughly evaluate stroke and its consequences, given the importance of the brain vasculature to study the effects of abnormal brain perfusion and given the involvement of other systems as well [5]. For these reasons animal models are required to reproduce specific aspects of human disease, to understand the complex pathophysiology of stroke and to find efficacious preventive and therapeutic approaches $[6,7]$.

Experimental animal models encompass today:

i Models addressing specific risk factors such as atherosclerosis, hypercholesterolemia, hypertension, hyper-homocysteinemia, obesity and aging;

ii Models mimicking single-gene disorders associated with ischemic stroke, such as cerebral autosomal dominant arteriopathy with subcortical infarcts and leucoencephalopathy (CADASIL);

iii Focal and global cerebral ischemia models that mimic specific aspects of human stroke (these models are 
discussed in the second part of the review: "Part two: Modeling cerebral ischemia").

The models described in i.) and ii.) are used to study the relationship between risk factors (modifiable and not modifiable) and stroke with the overall aim to understand and to develop efficacious treatments to avoid the occurrence of cerebral ischemic damage. In these models, variables can be taken under strict control and researchers may address specific questions about pathologic events leading to stroke [8].

\section{MODELS FOR STUDYING STROKE RELATED RISK FACTORS}

\section{Atherosclerosis and Associated Risk Factors}

Atherosclerosis is a chronic inflammatory response of arterial blood vessels characterized by intimal lesions called fibro-fatty plaques that protrude into the lumen of the vessel, weaken the underlying media and undergo a series of complications [9]. Although the process of atherogenesis has been thought to consist largely of the accumulation of lipids within the arterial wall, the pathophysiology of atherosclerosis is more complex.

Endothelial dysfunction is the first initiating step. Different mechanisms including elevated and modified LDL, hypertension, free radicals as induced by cigarette smoking and type II diabetes, genetic alterations elevated plasma levels of homocysteine, infective microorganisms and combinations of these risk factors can lead to endothelial dysfunction [10, 11].

The damage induced by these factors leads to alterations of the intrinsic properties of endothelium. As such, vascular permeability and the adhesiveness to leukocytes and platelets are increased, and anticoagulant properties are altered.

The persistence of irritative cues on endothelial cells cause local inflammatory responses that stimulate the migration and proliferation of smooth- muscle cells leading in the long run to the remodeling of the vessel. Characteristic of this initial rearrangement in the coronary arteries is that the internal diameter of the lumen remains largely unaltered at the expense of a dilatation towards outside [12]. In the carotid arteries the irritative cues on endothelial cells augment the intimal-medial wall thickness (IMT), that is a particularly relevant marker of subclinical atherosclerosis [13].

The persistent inflammatory reaction attracts more and more macrophages and lymphocytes from the blood that multiply within the lesion. These monocyte-derived macrophages and $\mathrm{T}$ lymphocytes induce through the sustained release of cytokines, chemokines and growth factors, a remodeling of the vessel wall together with the proliferation of smooth-muscle cells [14]. At a certain point, the advanced lesion called "atherosclerotic plaque" protrudes into the lumen of the vessel altering blood flow. A fibrous cap overlying a core of lipid core and necrotic tissue is characteristic of this plaque.

If the plaque spontaneously ruptures blood coagulation is locally activated and may cause a complete occlusion of the vessel or induce distal thromboembolism [15]. Because atherosclerosis is a multifactorial disease, understanding the underlying genetics and role of environmental factors may help to explain differences in susceptibility to agents that cause this disease. All the current mouse models of atherosclerosis are based on perturbations of lipoprotein metabolism through dietary and/or genetic manipulations. The models for atherosclerosis will therefore be explained in the section on hypercholesterolemia (a). Nonetheless it is worth considering that although hyperlipidemia is necessary for the development of atherosclerosis, many nonlipid factors can influence the severity and the characteristics of lesions.

\section{a. Hypercholesterolemia}

Deposits of low-density proteins in the arterial walls are an important trigger for the development of atherosclerotic disease [15]. Despite increased attention towards this risk factor and the use of pharmacological treatments to lower plasmatic cholesterol levels, atherosclerosis remains one of the principal causes of cardiovascular disease [16, 17]. The apolipoprotein E-deficient $\left(\right.$ apoE $^{-/}$) mouse, established in 1992 , is one of the most important animal models of atherosclerosis [18] because of its propensity to spontaneously develop atheromatous lesions when kept on a cholesterol-rich diet. The apoE is an important modulator of lipoprotein interactions with several receptors, including low-density lipoprotein (LDL) receptors and LDL-related receptor on the surface of several lipoproteins, including chylomicrons, VLDL and HDL particles [19].

$\mathrm{ApoE}^{-/-}$mice are characterized by increased plasma cholesterol levels and by the development of accelerated atherosclerosis with extensive lipid deposition on major arteries such as the aorta [20]. Similar to what has been observed in human atherosclerotic plaques apoE $\mathrm{E}^{-/-}$mice also have plaques that are heavily infiltrated by $\mathrm{CD}^{+} \mathrm{T}$ cells [21]. In these mice atherosclerotic changes of the vessel walls can be observed progressively during aging. Intermediate vascular lesions containing foam cells and smooth muscle cells can be found at 15 weeks, and fibrous plaques appear at 20 weeks of age.

The atherosclerotic process is further accelerated when mice are fed with cholesterol-rich high protein, high carbohydrate and high fat products, the so-called 'Western diet' [22]. The histological and morphological analysis of plaque progression and lesion size share similarities with human atherosclerotic lesions [21]. In particular, it has been recently described that old apoE $\mathrm{E}^{-/-}$mice develop plaques in the brachiocephalic arteries that closely resemble human plaques.

Murine studies on atherosclerotic lesions are nonetheless difficult as cholesterol metabolism, lipid profile, cardiovascular physiology, plaque pathology are different to that of humans. Although apoE ${ }^{-/-}$mice display vascular atherosclerotic changes they do not develop spontaneous thrombotic occlusions and/or embolic events [22]. Despite these limitations of the apoE $\mathrm{E}^{-/-}$mouse, it has been possible to study cholesterol absorption inhibitors such as ezetimibe [23], antihypertensive drugs, such as angiotensinogen converting enzyme inhibitors or angiotensin II receptor blockers [24], and antidiabetic drugs as rosiglitazone and trogliatiazone [22, 25]. This demonstrates once again that quite different risk factors contribute to plaque formation and that these can be addressed therapeutically.

Another important animal model in the study of hypercholesterolemia is the Apolipoprotein B (apoB) mouse. 
ApoB is the major protein directing the metabolic fate of both VLDL and LDL, and its increased plasma concentrations are associated with the development of cardiovascular diseases. The transgenic apoB mice that express human apoB have similar plasma concentrations to those of normolipidemic humans when fed on normal diet [26]. However when these mice are fed with the typical 'Western Diet' pronounced atherosclerosis develops with a higher extent in C57BL/6 female mice than males. Macrophage foam cells characterize primarily the atherosclerotic lesions that form [27].

While in humans the deficiency of LDL receptors (LDLR) leads to a dramatic phenotype of pronounced hypercholesterolemia with catastrophic clinical consequences, mice lacking the LDL receptor $\left(\mathrm{LDLR}^{-/}\right)$display only a modest hypercholesterolemia when fed on a normal diet [28]. As in the other model of hypercholesterolemia (apoE or apoB mice) also these mice develop atherosclerosis on the Western type diet. The lesions formed in these mice are of simple morphology and predominantly consist of lipid-laden macrophages [29].

A key component to the formation of the atherosclerotic lesion, which involves an inflammatory process, has also been studied extensively and targeted with various anti- inflammatory drugs (acetylsalicylic acid, sulindac, celecoxib) [30-32]. Mixed results on plaque size and progression have been observed in these studies and up to now it is not entirely clear whether anti-inflammatory drugs may have a beneficial role on the atherosclerotic plaque in humans [22].

Other experimental studies on atherosclerosis have used the apo $\mathrm{E}^{-/-}$mouse as starting basis for double knockout mice or transgene to study genes involved in lipid metabolism (e.g. acyl CoA cholesterol acyl transferase-2 [33], ATP binding cassette $(\mathrm{ABC})$ transporter $\mathrm{ABCA} 1$ [34], low density lipoprotein receptor [35]), inflammation (e.g. C-reactive protein [36], inducible nitric oxide synthase (iNOS) [37], endothelial nitric oxide synthase (eNOS)[38], interleukin-1 beta [39]) and blood hemostasis (e.g. fibrinogen [40], plasminogen [41], plasminogen activator inhibitor-1 [42]). See also reference [43] for an extensive review on atherosclerosis mouse models.

\section{b. Modeling Arterial Hypertension}

Arterial hypertension, defined as untreated systolic pressure of $\geq 140 \mathrm{mmHg}$, diastolic pressure of $\geq 90 \mathrm{mmHg}$ or prescription of antihypertensive drugs, affects nearly one in three adults in the United States. Blood pressure, particularly systolic blood pressure, increases with age [44]. Hypertension can be subdivided into two main categories: primary hypertension and secondary hypertension. Primary, essential or idiopathic hypertension is assumed when no specific cause can be found. In secondary hypertension, elevated blood pressure levels are due to specific reasons (most often renal dysfunction, hormone alterations and/or sleep apnea) that if identified can be corrected [45].

Hypertension is the most important risk factor for stroke and a direct correlation between blood pressure values and stroke risk has been described [46, 47]. Subjects with blood pressure lower than $120 / 80 \mathrm{mmHg}$ have about half the lifetime risk of stroke compared to subjects with higher blood pressure [48]. The relationship between blood pressure and cardiovascular risk is considered to be continuous, consistent and independent of other risk factors. [49].

Although recent advances in blood pressure control (data from the National Health and Nutrition Examination Survey, NHANES 1999-2004) showed that of the subjects with hypertension aged 18 and older, $71.8 \%$ were aware of their condition, only $61.4 \%$ were under current treatment and $35.1 \%$ had arterial pressure levels that were reasonably controlled (data from National Center for Health Statistics and National Heart, Lung and Blood Institute). Because of the high prevalence of hypertension and its high direct and indirect costs (estimated to be of $\$ 69.4$ billion for 2008) identifying genetic and environmental risk factors is not only important for the prevention of CVD but also for the development of new pharmacological tools aimed at preventing late complications [50].

Over the past 50 years various animal models of hypertension have been developed, predominantly in the rat. Different rat models can either be grouped according to their capacity to mimic the etiology of hypertension (primary vs. secondary and genetic vs. environmental) or according to the resulting end-organ damage, cardiac failure vs. renal failure vs. vascular injury. With the use of these models, analysis of genetic susceptibility factors to multifactor diseases has become feasible as animal studies avoid (1) genetic heterogeneity, (2) environmental noise, and (3) the poor statistical power related to small patient populations [51].

Spontaneously hypertensive rats (SHR) represent the animal model most widely used in hypertension studies. They mimic in particular the human form of primary hypertension although the Mendelian type of inheritance that characterizes hypertension in the SHR is rarely encountered in humans. Okakamoto and Aoki [52] obtained the SHR rats by inbreeding Wistar rats showing the highest blood pressure. These animals develop increases in blood pressure beginning at six to seven weeks of age and reach a stable level of hypertension (reach systolic blood pressures of 180- 200 $\mathrm{mmHg}$ ) by 17 to 19 weeks.

The SHR develop many features of hypertensive endorgan damage as cardiac hypertrophy, present in $30 \%$ of cases [53], heart failure present in $60 \%$ of the rats at the age of 18- 24 months, renal proteinuria, decreased creatinine clearance as signs of renal dysfunction [54, 55]. However, they do not exhibit gross vascular problems, apart from consistently impaired endothelium relaxation [56]. They have no tendency to develop strokes, macroscopic atherosclerosis or vascular thrombosis. Mean survival of this strain is of 10-21 months. Interestingly various anti-hypertensive drugs like calcium antagonists, inhibitors of the renin- angiotensin system and direct vasodilators can lower consistently blood pressure in the SHR strain. However end organ damage seems not to be prevented by any kind of treatment [57].

Another strain, the spontaneous hypertensive stroke prone rat(SHR-SP) exhibits an early onset of hypertension, and $80 \%$ of animals experience stroke between 9 and 13 months of age [58]. There are many pathogenetic similarities between strokes in SHR-SP rats and humans [59]. On the SHR-SP, it was in fact possible to identify one of the genetic components responsible for large infarct volumes in response to a focal ischemic insult, independently from blood 
pressure values. The genes encoding atrial and brain natriuretic factor were identified in this case. These genes have well- established vasoactive properties and might be involved in the control of vasoreactivity, growth and remodeling of cerebral vessels [60].

Further, the SHR-SP exhibits salt-sensitivity, increased vascular release of super oxide and decreased total plasma antioxidant capacity. The super oxide release in the SHR-SP rats has been found to inactivate nitric oxide in mesenteric arteries and to be directly correlated with hypertension. Interestingly, administration of super oxide dismutase (SOD) returns the bioactive nitric oxide levels to normal together with blood pressure [61]. These data suggest that oxidative stress plays an important role in severe hypertension in saltloaded SHR-SP rats and its associated vascular damage [62].

To help to clarify the role of individual genes, other animal models of hypertension were developed. The transgenic rat overexpressing the mouse Ren-2 gene ((TGRmREN2)27) is important in hypertension research as, in contrast to the SHR and SHR-SP rat, it is a genetically inherited form of hypertension for which the responsible gene is known. Nonetheless the exact mechanism via which this mutation leads to hypertension is not clear. That hypertension usually depends not on a single candidate gene but on a variety of genes can be clearly shown by the fact that the severity of hypertension in (TGR-mREN2)27 rats is dependent on the genetic background. For example, SpragueDawley rats develop an accelerated and more malignant hypertension compared with Lewis rats that do not develop hypertension [63].

A further animal model of primary genetic hypertension is the Dahl salt- sensitive rat. This rat develops severe and fatal hypertension when it receives a high salt diet. The increased sensitivity to salt is also present when these rats are fed with normal diet as they also develop hypertension. Genetic analysis has revealed a role for the angiotensin converting enzyme (ACE) and atrial natriuretic factor (ANP) receptor genes. Cardiac hypertrophy develops in about $32 \%$ of rats and cardiac heart failure evolves early after its onset (about 4-5 months of age) [64, 65].

To model secondary renal hypertension in the rat the most used method is to occlude the renal artery with a clip, leaving either the controlateral kidney intact ('two-kidneys one-clip') or removing this second kidney ('one-kidney oneclip) $[66,67]$. Although clipping of the renal artery has also been used in the dog, the rat model is much more reliable. In the rat model, like in human disease, hypertension is chronic, while in the dog the rapid formation of vessel collaterals accounts for its short duration. Cardiac hypertrophy that affects approximately $25-50 \%$ of rats subjected to the clipping can be attenuated by administration of renin- angiotensin inhibitors and calcium antagonists, but diuretics and betablockers are not effective. As such, animal models of hypertension offer the opportunity to investigate not only the pathophysiology of hypertension, but also to the effects of anti-hypertensive drugs. Further, they can be used for inducing stroke, as has been made with the SHR-SP rat, to study the complex vascular response that follows stroke $[60,68]$.

\section{c. Hyperhomocysteinemia}

High levels of plasma homocysteine represent a relevant risk factor for cardiovascular disease, stroke, and venous thromboembolism [69, 70]. Although severe forms of hyperhomocysteinemia (plasma concentrations above $100 \mu \mathrm{mol}$ $\mathrm{L}^{-1}$ ) may result from mutations of enzymes involved in the metabolism of homocysteine such as cystathionine $\beta$ synthetase (CBS) or 5,10-methylenetetrahydrofolate reductase (MTHFR), also the deficiency of cofactors (folic acid, vitamin B6 and B12) can result in the mild forms of hyperhomocysteinemia characterized by a plasma concentration of $12-50 \mu \mathrm{mol} \mathrm{L}^{-1}$. Patients affected by severe forms of hyperhomocysteinemia have, if untreated, $50 \%$ of chance of developing a major vascular event (myocardial infarction, stroke, or venous thromboembolism) before the age of 30 years [71].

Also mild hyperhomocysteinemia, as pointed out by recent epidemiological studies, is considered as a risk factor for stroke, cardiovascular disease, and venous thromboembolism [72].

The underlying pathophysiological mechanism of hyperhomocysteinemia has been suggested to be enhanced atherothrombosis. Homocysteine causes in fact endothelial cell dysfunction and induces apoptosis in endothelial and smooth muscle cells. The strongest evidence that homocysteine plays a causative role in atherothrombosis has been gained from studies of hyperhomocysteinemia in animal models in the last ten years.

The first genetic model of hyperhomocysteinemia in mice was developed in 1995 through targeted disruption of the CBS gene thereby establishing a severe form of hyperhomocysteinemia induced by homozygous CBS-deficiency (plasma levels of homocysteine elevated by 40 -fold with plasma concentrations above $200 \mu \mathrm{mol} \mathrm{L}^{-1}$ ) and a mild form in heterozygous CBS deficiency (plasma concentration 6-15 $\mu \mathrm{mol} \mathrm{L}^{-1}$ ) [73]. Severe growth retardation, hepatic steatosis and dislocation of the lens are characteristics of the homozygous mouse model. Very similar clinical features characterize also the natural history of patients with homocystinuria [74]. On the other hand, heterozygous mice with twice the normal plasmatic homocysteine levels are apparently healthy, thereby making them interesting models for studying mild forms of hyperhomocysteinemia. Notably heterozygous CBS- deficient mice display endothelial dysfunctions but do not show increased risk for atherosclerotic plaque formation [73].

Another model of hyperhomocysteinemia is the MTHFRdeficient mouse. In contrast to the CBS-deficient mouse, heterozygous and homozygous MTHGR-deficient animals show early atherosclerotic lesions. Despite the presence of atherosclerotic plaques, these mice do not exhibit increased lipid plasma levels, thereby suggesting that hyperhomocysteinemia contributes indirectly to the development of atherosclerosis [75].

In atherosclerosis prone animals like apoE ${ }^{-/-}$mice, hyperhomocysteinemia accelerates the development of atherosclerosis through the enhanced expression of inflammatory mediators (e.g. receptor for advanced glycation end products (RAGE), vascular cell adhesion molecule-1 (VCAM-1), 
Table 1. Animal Models for Studying Risk Factors and Therapies for Stroke

\begin{tabular}{|l|l|l|l|}
\hline Model for & Model name & Animal species available & Gene/s involved \\
\hline \hline Hypercholesterolemia & ApoE deficient mouse & Mouse & ApoE \\
\hline & ApoB mutant mouse & Mouse & ApoB \\
\hline Hyperhomocysteinemia & LDLR deficient mouse & Mouse & LDLR \\
\hline & CBS deficient mouse & Mouse & CBS \\
\hline Primary hypertension & MTHFR deficient mouse & Mouse & MTHFR \\
\hline & SHR & Rat & Gene not known \\
\hline & SHR-SP & Rat & Gene not known \\
\hline & Ren-2 transgenic rat (TGR-mREN2)27 & Ren-2 \\
\hline Secondary hypertension & Dahl sensitive rat & Rat & ACE and ANF \\
\hline & Two- kidney one clip & Dog, rat, mouse & - \\
\hline Age & One- kidney one clip & Dog, rat, mouse & - \\
\hline & Spontaneously aged (> 18 months) & Rat, mouse & - \\
\hline CADASIL & Senescence-accelerated mice & Mouse & Genes not known \\
\hline
\end{tabular}

Abbreviations: ApoE, apolipoprotein E; ApoB, apolipoproteinB; LDLR, Low density lipoprotein receptor; CBS, Cystathionine beta- synthetase; MTHFR, Methylenetetrahydrofolate reductase; SHR, Spontaneously hypertensive rat; SHR-SP, Spontaneously hypertensive rat- stroke prone; ACE, Angiotension converting exzyme; ANF, atrial natriuretic factor; CADASIL, cerebral autosomal dominant arteriopathy with subcortical infarcts and leukoencephalopathy.

tissue factor (TF), and matrix metalloproteinase-9 (MMP-9) [76]) and by the dysregulation of lipid metabolism [77]. A major goal of current research using these animal models is to uncover the molecular and cellular mechanisms underlying the atherogenic effects of hyperhomocysteinemia and to develop efficacious treatments for lowering the increased risk of hyperhomocysteinemic patients [78, 79]. In fact, although today the homocysteine level can be reduced through adequate diet, no proof is available that lowering mild elevated homocysteine levels as primary prevention decreases the cerebro- or cardiovascular risk. (The Heart Outcomes Prevention Evaluation, HOPE 2 Investigators 2006) [80]. Also in the secondary prevention for stroke there are currently no recommendations to treat elevated homocysteine levels with vitamins or folic acid [81, 82]. We hope that the large Australian study (VITATOPS) in the next few years with their data together with increased insight in the pathogenesis of hyperhomocysteinemia will make the image round.

\section{Aging as Risk Factor for Stroke}

Age accounts for a so-called not modifiable risk factor for stroke. The probability of having a stroke in fact approximately doubles for each decade of life after age 55 . (National Center for Health Statistics, http://www.cdc.gov/ nchs/fastats/deaths.htm)

Rats and mice are the species of choice for most animal studies on aging. Most rodents used in aging studies must be cared for and maintained for 2 or more years before they can be used in experiments therefore requiring considerable financial investment [83].

Other animal models for aging include different strains of the senescence-accelerated mice (SAM) that by the age of 6 months undergo significant aging changes as senile amyloidosis, deficits in learning and memory, senile osteoporosis together with various neoplastic diseases [84-86].

\section{Single-Gene Disorders Associated with Stroke: CADASIL}

Cerebral Autosomal Dominant Arteriopathy with Subcortical Infarcts and Leukoencephalopathy, CADASIL, is a heritable small-vessel disease caused by mutations in NOTCH3 [87]. Clinically CADASIL comprises recurrent strokes and transient ischemic attacks, progressive cognitive impairment, and psychiatric disturbance with onset usually in the third to sixth decade. The bilateral involvement of the anterior temporal white matter and external capsule is a characteristic feature in CADASIL [88]. Pathological examination reveals multiple small, deep cerebral infarcts, leukoencephalopathy and a non-atherosclerotic, non-amyloid angiopathy of the small cerebral arteries caused by the degeneration of vascular smooth muscle cells and abnormal accumulation of electron dense granular material [89].

Recently a transgenic mouse model for CADASIL has been developed in which the full-length human Notch3 carrying the Arg90Cys mutation is expressed under the SM22 promoter in vascular smooth muscle cells [90]. Although transgenic mice showed no evidence of prominent brain parenchyma damage, both cerebral and peripheral arteries were demonstrated to contain granular material deposits and Notch3 accumulation typical of CADASIL. This animal model will hopefully enable to better understand the underlying mechanisms of this often devastating illness.

Animal models for stroke risk factors discussed have been summarized in Table $\mathbf{1}$.

\section{CONCLUSION}

This article provides a review of many (but not all) models for stroke risk factors currently in use. The use of one of these models offer an opportunity to investigate mechanisms, prevention, and treatment of specific risk factors that are related to stroke. Further the effects of genes, gene products, and proteins in the development of vascular damage can be 
determined. However, no model is able to mimic and describe human stroke: different models are in fact of great value in modeling the different risk factors and aspects of human disease. The choice of using one model rather than another depends essentially on the target of the investigation. Nonetheless it is often useful to evaluate more than one model in different species to overcome limitations of single models. Future development foresee the development of new models for risk factors, the more extended use of genetic manipulation for designing new models. This with the aim of creating more and more tools for a better understanding and mimicry of stroke related risk factors. At present in fact no stroke model is really able to mimic vessel disease that is a major cause of disability and mortality in the older population.

It must also be critically mentioned that until the present stage, not many experimental stroke studies made use of the pool of transgenic animals at vascular risk that were described in this review. Future studies should consider more and more the use of aged animals where prolonged arterial injury and a generalized aging of all the tissues better mimics human stroke.

\section{REFERENCES}

[1] Lopez AD, Mathers CD, Ezzati M, Jamison DT, Murray CJ. Global and regional burden of disease and risk factors, 2001: systematic analysis of population health data. Lancet 2006; 367(9524): 174757.

[2] Garber K. Stroke treatment--light at the end of the tunnel? Nat Biotechnol 2007; 25(8): 838-40.

[3] Taylor TN, Davis PH, Torner JC, Holmes J, Meyer JW, Jacobson MF. Lifetime cost of stroke in the United States. Stroke 1996; 27(9): 1459-66.

[4] Hachinski V. The 2005 Thomas Willis Lecture: stroke and vascular cognitive impairment: a transdisciplinary, translational and transactional approach. Stroke 2007; 38(4): 1396.

[5] Graham SM, McCullough LD, Murphy SJ. Animal models of ischemic stroke: balancing experimental aims and animal care. Comp Med 2004; 54(5): 486-96.

[6] Carmichael ST. Rodent models of focal stroke: size, mechanism, and purpose. NeuroRx 2005; 2(3): 396-409.

[7] Hainsworth AH, Markus HS. Do in vivo experimental models reflect human cerebral small vessel disease? A systematic review. J Cereb Blood Flow Metab 2008; 28(12): 1877-91.

[8] Durukan A, Tatlisumak T. Acute ischemic stroke: overview of major experimental rodent models, pathophysiology, and therapy of focal cerebral ischemia. Pharmacol Biochem Behav 2007; 87(1): 179-97.

[9] Kumar V, Abbas AK, Fausto N, Robbins SL, Cotran RSRpbod. Robbins and Cotran pathologic basis of disease. $7^{\text {th }}$ ed. Kumar V, Abbas, AK, Fausto N, Perkins JA, Eds. Philadelphia, Pa., London: Elsevier Saunders 2005.

[10] Ross R. The pathogenesis of atherosclerosis: a perspective for the 1990s. Nature 1993; 362(6423): 801-9.

[11] Ross R. George lyman duff memorial lecture. Atherosclerosis: a problem of the biology of arterial wall cells and their interactions with blood components. Arteriosclerosis 1981; 1(5): 293-311.

[12] Glagov S, Weisenberg E, Zarins CK, Stankunavicius R, Kolettis GJ. Compensatory enlargement of human atherosclerotic coronary arteries. N Engl J Med 1987; 316(22): 1371-5.

[13] Humphries SE, Morgan L. Genetic risk factors for stroke and carotid atherosclerosis: insights into pathophysiology from candidate gene approaches. Lancet Neurol 2004; 3(4): 227-35.

[14] Hermann DM, Matter CM. Tissue plasminogen activator-induced reperfusion injury after stroke revisited. Circulation 2007; 116(4): 363-5.

[15] Ross R. Atherosclerosis--an inflammatory disease. N Engl J Med 1999; 340(2): 115-26.

[16] Breslow JL. Cardiovascular disease burden increases, NIH funding decreases. Nat Med 1997; 3(6): 600-1.
[17] Braunwald E. Shattuck lecture--cardiovascular medicine at the turn of the millennium: triumphs, concerns, and opportunities. $\mathrm{N}$ Engl $\mathrm{J}$ Med 1997 6; 337(19): 1360-9.

[18] Plump AS, Smith JD, Hayek T, et al. Severe hypercholesterolemia and atherosclerosis in apolipoprotein E-deficient mice created by homologous recombination in ES cells. Cell 1992; 71(2): 343-53.

[19] Mahley RW. Apolipoprotein E: cholesterol transport protein with expanding role in cell biology. Science 1988; 240(4852): 622-30.

[20] Moghadasian MH, McManus BM. Pathophysiology of apolipoprotein $\mathrm{E}$ deficiency in mice: relevance to apo E-related disorders in humans. FASEB J 2001; 15(14): 2623-30.

[21] Reddick RL, Zhang SH, Maeda N. Atherosclerosis in mice lacking apo E. Evaluation of lesional development and progression. Arterioscler Thromb1994 14(1): 141-7.

[22] Meir KS, Leitersdorf E. Atherosclerosis in the apolipoprotein-Edeficient mouse: a decade of progress. Arterioscler Thromb Vasc Biol 2004; 24(6): 1006-14

[23] Davis HR, Jr, Compton DS, Hoos L, Tetzloff G. Ezetimibe, a potent cholesterol absorption inhibitor, inhibits the development of atherosclerosis in ApoE knockout mice . Arterioscler Thromb Vasc Biol 2001; 21(12): 2032-8.

[24] Hayek T, Attias J, Smith J, Breslow JL, Keidar S. Antiatherosclerotic and antioxidative effects of captopril in apolipoprotein Edeficient mice. J Cardiovas pharmacol 1998; 31(4): 540-4.

[25] Chen Z, Ishibashi S, Perrey S, et al. Troglitazone inhibits atherosclerosis in apolipoprotein E-knockout mice: pleiotropic effects on CD36 expression and HDL. Arterioscler Thromb Vasc Biol 2001; 21(3): 372-7.

[26] Linton MF, Farese RV, Jr, Chiesa G, et al. Transgenic mice expressing high plasma concentrations of human apolipoprotein B100 and lipoprotein(a). J Clin investig 1993; 92(6): 3029-37.

[27] Purcell-Huynh DA, Farese RV, Jr., Johnson DF, et al. Transgenic mice expressing high levels of human apolipoprotein B develop severe atherosclerotic lesions in response to a high-fat diet. J Clin Invest 1995; 95(5): 2246-57.

[28] Ishibashi S, Brown MS, Goldstein JL, Gerard RD, Hammer RE, Herz J. Hypercholesterolemia in low density lipoprotein receptor knockout mice and its reversal by adenovirus-mediated gene delivery. J Clin Invest1993; 92(2): 883-93.

[29] Ishibashi S, Goldstein JL, Brown MS, Herz J, Burns DK. Massive xanthomatosis and atherosclerosis in cholesterol-fed low density lipoprotein receptor-negative mice. J Clin Invest 1994; 93(5): 1885-93.

[30] Paul A, Calleja L, Camps J, et al. The continuous administration of aspirin attenuates atherosclerosis in apolipoprotein E-deficient mice. Life Sci 2000; 68(4): 457-65.

[31] Reis ED, Roque M, Dansky H, et al. Sulindac inhibits neointimal formation after arterial injury in wild-type and apolipoprotein Edeficient mice. Proc Natl Acad Sci USA 2000; 97(23): 12764-9.

[32] Olesen M, Kwong E, Meztli A, et al. No effect of cyclooxygenase inhibition on plaque size in atherosclerosis-prone mice. Scand Cardiovase J 2002; 36(6): 362-7.

[33] Willner EL, Tow B, Buhman KK, et al. Deficiency of acyl CoA: cholesterol acyltransferase 2 prevents atherosclerosis in apolipoprotein E-deficient mice. Proc Natl Acad Sci USA 2003; 100(3): 12627.

[34] Aiello RJ, Brees D, Bourassa PA, et al. Increased atherosclerosis in hyperlipidemic mice with inactivation of ABCA1 in macrophages. Arterioscler Thromb Vasc Biol 2002; 22(4): 630-7.

[35] Bonthu S, Heistad DD, Chappell DA, Lamping KG, Faraci FM. Atherosclerosis, vascular remodeling, and impairment of endothelium-dependent relaxation in genetically altered hyperlipidemic mice. Arterioscler Thromb Vasc Biol 1997 ; 17(11): 2333-40.

[36] Paul A, Ko KW, Li L, et al. C-reactive protein accelerates the progression of atherosclerosis in apolipoprotein E-deficient mice. Circulation 2004; 109(5): 647-55.

[37] Kuhlencordt PJ, Chen J, Han F, Astern J, Huang PL. Genetic deficiency of inducible nitric oxide synthase reduces atherosclerosis and lowers plasma lipid peroxides in apolipoprotein E-knockout mice. Circulation 2001; 103(25): 3099-104.

[38] Kuhlencordt PJ, Gyurko R, Han F, et al. Accelerated atherosclerosis, aortic aneurysm formation, and ischemic heart disease in apolipoprotein E/endothelial nitric oxide synthase double-knockout mice. Circulation 2001; 104(4): 448-54. 
[39] Kirii H, Niwa T, Yamada Y, et al. Lack of interleukin-1beta decreases the severity of atherosclerosis in ApoE-deficient mice. Arterioscler Thromb Vasc Biol 2003; 23(4): 656-60.

[40] Xiao Q, Danton MJ, Witte DP, Kowala MC, Valentine MT, Degen JL. Fibrinogen deficiency is compatible with the development of atherosclerosis in mice. J Clin Invest 1998; 101(5): 1184-94.

[41] Xiao Q, Danton MJ, Witte DP, et al. Plasminogen deficiency accelerates vessel wall disease in mice predisposed to atherosclerosis. Proc Natl Acad Sci USA 1997; 94(19): 10335-40.

[42] Luttun A, Lupu F, Storkebaum E, et al. Lack of plasminogen activator inhibitor-1 promotes growth and abnormal matrix remodeling of advanced atherosclerotic plaques in apolipoprotein E-deficient mice. Arterioscler Thromb Vasc Biol 2002; 22(3): 499-505.

[43] Daugherty A. Mouse models of atherosclerosis. Am J Med Sci 2002; 323(1): 3-10.

[44] Fields LE, Burt VL, Cutler JA, Hughes J, Roccella EJ, Sorlie P. The burden of adult hypertension in the United States 1999 to 2000: a rising tide. Hypertension 2004; 44(4): 398-404.

[45] Fauci AS. Harrison's principles of internal medicine. $17^{\text {th }}$ ed. New York: McGraw-Hill Medical ; London : McGraw-Hill [distributor] 2008.

[46] Whisnant JP. Modeling of risk factors for ischemic stroke. The Willis Lecture. Stroke 1997; 28(9): 1840-4.

[47] Adab P, Cheng KK, Jiang CQ, Zhang WS, Lam TH. Age-specific relevance of usual blood pressure to vascular mortality. Lancet 2003; 361(9366): 1391; author reply -2 .

[48] Seshadri S, Beiser A, Kelly-Hayes M, et al. The lifetime risk of stroke: estimates from the Framingham Study. Stroke 2006; 37(2): 345-50.

[49] Chobanian AV, Bakris GL, Black HR, et al. The seventh report of the joint national committee on prevention, detection, evaluation, and treatment of high blood pressure: the JNC 7 report. JAMA 2003; 289(19): 2560-72.

[50] Goldstein LB, Adams R, Alberts MJ, et al. Primary prevention of ischemic stroke: a guideline from the American Heart Association/American Stroke Association Stroke Council: cosponsored by the Atherosclerotic Peripheral Vascular Disease Interdisciplinary Working Group; Cardiovascular Nursing Council; Clinical Cardiology Council; Nutrition, Physical Activity, and Metabolism Council; and the Quality of Care and Outcomes Research Interdisciplinary Working Group. Circulation 2006; 113(24): e873-923.

[51] Nabika T, Cui Z, Masuda J. The stroke-prone spontaneously hypertensive rat: how good is it as a model for cerebrovascular diseases? Cell Mol Neurobiol 2004; 24(5): 639-46.

[52] Okamoto K, Aoki K. Development of a strain of spontaneously hypertensive rats. Jpn Circ J 1963; 27: 282-93.

[53] Conrad CH, Brooks WW, Robinson KG, Bing OH. Impaired myocardial function in spontaneously hypertensive rats with heart failure. Am J Physiol 1991; 260(1 Pt 2): H136-45.

[54] Galaske RG, Van Liew JB, Feld LG. Filtration and reabsorption of endogenous low-molecular-weight protein in the rat kidney. Kidney Int 1979; 16(3): 394-403.

[55] Komatsu K, Frohlich ED, Ono H, Ono Y, Numabe A, Willis GW. Glomerular dynamics and morphology of aged spontaneously hypertensive rats: effects of angiotensin-converting enzyme inhibition. Hypertension 1995 25(2): 207-13.

[56] Luscher TF, Aarhus LL, Vanhoutte PM. Indomethacin improves the impaired endothelium-dependent relaxations in small mesenteric arteries of the spontaneously hypertensive rat. Am J Hypertens 1990; 3(1): 55-8.

[57] Pinto YM, Paul M, Ganten D. Lessons from rat models of hypertension: from Goldblatt to genetic engineering. Cardiovasc Res 1998; 39(1): 77-88.

[58] Ganten D, Birkenhäger WH, Reid JL. Handbook of hypertension. Experimental and genetic models of hypertension. Amsterdam [u.a.]: Elsevier 1994; Vol. 16.

[59] Carr FJ, McBride MW, Carswell HV, et al. Genetic aspects of stroke: human and experimental studies. J Cereb Blood Flow Metab 2002; 22(7): 767-73.

[60] Jeffs B, Clark JS, Anderson NH, et al. Sensitivity to cerebral ischaemic insult in a rat model of stroke is determined by a single genetic locus. Nat Genet1997; 16(4): 364-7.

[61] Tschudi MR, Mesaros S, Luscher TF, Malinski T. Direct in situ measurement of nitric oxide in mesenteric resistance arteries. Increased decomposition by superoxide in hypertension. Hypertension 1996; 27(1): 32-5.
[62] Manning RD, Jr, Meng S, Tian N. Renal and vascular oxidative stress and salt-sensitivity of arterial pressure. Acta Physiol Scand 2003; 179(3): 243-50.

[63] Whitworth CE, Fleming S, Cumming AD, et al. Spontaneous development of malignant phase hypertension in transgenic Ren-2 rats. Kidney Intl 1994; 46(6): 1528-32.

[64] Rapp JP. Dahl salt-susceptible and salt-resistant rats: a review. Hypertension 1982; 4(6): 753-63.

[65] Deng Y, Rapp JP. Cosegregation of blood pressure with angiotensin converting enzyme and atrial natriuretic peptide receptor genes using Dahl salt-sensitive rats. Nat Genet 1992; 1(4): 267-72.

[66] Swales JD, Tange JD. The influence of acute sodium depletion on experimental hypertension in the rat. J Lab Clin Med 1971; 78(3): 369-79.

[67] Deodhar SD, Haas E, Goldblatt H. Production of antirenin to homologous renin and its effect of experimental renal hypertension. J Exper Med 1964; 119: 425-32.

[68] Mies G, Hermann D, Ganten U, Hossmann KA. Hemodynamics and metabolism in stroke-prone spontaneously hypertensive rats before manifestation of brain infarcts. J Cereb Blood Flow Metab 1999; 19(11): 1238-46.

[69] McCully KS. Homocysteine and vascular disease. Nat Med 1996; 2(4): 386-9.

[70] Selhub J, Jacques PF, Bostom AG, et al. Association between plasma homocysteine concentrations and extracranial carotid-artery stenosis. N Engl J Med 1995; 332(5): 286-91.

[71] Mudd SH, Skovby F, Levy HL, et al. The natural history of homocystinuria due to cystathionine beta-synthase deficiency. Am J Hum Genet 1985; 37(1): 1-31.

[72] Homocysteine Studies Collaboration. Homocysteine and risk of ischemic heart disease and stroke: a meta-analysis. JAMA 2002; 288(16): 2015-22.

[73] Watanabe M, Osada J, Aratani Y. Mice deficient in cystathionine beta-synthase: animal models for mild and severe homocyst(e)inemia. Proc Natl Acad Sci USA 1995; 92(5): 1585-9.

[74] Welch GN, Loscalzo J. Homocysteine and atherothrombosis. N Engl J Med 1998; 338(15): 1042-50.

[75] Chen Z, Karaplis AC, Ackerman SL, et al. Mice deficient in methylenetetrahydrofolate reductase exhibit hyperhomocysteinemia and decreased methylation capacity, with neuropathology and aortic lipid deposition. Hum Mol Genet 2001; 10(5): 433-43.

[76] Hofmann MA, Lalla E, Lu Y, et al. Hyperhomocysteinemia enhances vascular inflammation and accelerates atherosclerosis in a murine model. J Clin Investig 2001; 107(6): 675-83.

[77] Werstuck GH, Lentz SR, Dayal S, et al. Homocysteine-induced endoplasmic reticulum stress causes dysregulation of the cholesterol and triglyceride biosynthetic pathways. J Clin Invest 2001; 107(10): 1263-73

[78] Austin RC, Lentz SR, Werstuck GH. Role of hyperhomocysteinemia in endothelial dysfunction and atherothrombotic disease. Cell Death Differ 2004; 11(Suppl 1): S56-64.

[79] Lentz SR. Mechanisms of homocysteine-induced atherothrombosis J Thromb Haemost 2005; 3(8): 1646-54.

[80] Lonn E, Yusuf S, Arnold MJ, et al. Homocysteine lowering with folic acid and B vitamins in vascular disease. N Engl J Med 2006; 354(15): 1567-77.

[81] Bonaa KH, Njolstad I, Ueland PM, et al. Homocysteine lowering and cardiovascular events after acute myocardial infarction. $\mathrm{N}$ Engl J Med 2006 13; 354(15): 1578-88

[82] Toole JF, Malinow MR, Chambless LE, et al. Lowering homocysteine in patients with ischemic stroke to prevent recurrent stroke, myocardial infarction, and death: the Vitamin Intervention for Stroke Prevention (VISP) randomized controlled trial. JAMA 2004; 291(5): 565-75.

[83] Sprott RL, Ramirez I. Current inbred and hybrid rat and mouse models for gereontological research. ILAR journal / National Research Council, Institute of Laboratory Animal Resources1997; 38(3): 104-9.

[84] Takeda T, Hosokawa M, Takeshita S, et al. A new murine model of accelerated senescence. Mech Ageing Dev 1981; 17(2): 183-94

[85] Takeda T, Matsushita T, Kurozumi M, Takemura K, Higuchi K, Hosokawa M. Pathobiology of the senescence-accelerated mouse (SAM). Expergerontology 1997; 32(1-2): 117-27.

[86] Takeda T, Higuchi K, Hosokawa M. Senescence-accelerated Mouse (SAM): with special reference to development and patho- 
logical phenotypes. ILAR journal / National Research Council, Institute of Laboratory Animal Resources 1997; 38(3): 109-18.

[87] Joutel A, Corpechot C, Ducros A, et al. Notch3 mutations in CADASIL, a hereditary adult-onset condition causing stroke and dementia. Nature 1996; 383(6602): 707-10.

[88] Dichgans M. Genetics of ischaemic stroke. Lancet Neurol 2007; 6(2): 149-61.

[89] Baudrimont M, Dubas F, Joutel A, Tournier-Lasserve E, Bousser MG. Autosomal dominant leukoencephalopathy and subcortical ischemic stroke: a clinicopathological study. Stroke 1993; 24(1): 122-5.

[90] Ruchoux MM, Domenga V, Brulin P, et al. Transgenic mice expressing mutant Notch3 develop vascular alterations characteristic of cerebral autosomal dominant arteriopathy with subcortical infarcts and leukoencephalopathy. Am J Pathol 2003; 162(1): 329-42.

Received: May 11, 2009

Revised: December 16, 2009

Accepted: December 22, 2009

(C) Bacigaluppi et al.; Licensee Bentham Open.

This is an open access article licensed under the terms of the Creative Commons Attribution Non-Commercial License (http://creativecommons.org/licenses/by-nc/3.0/) which permits unrestricted, non-commercial use, distribution and reproduction in any medium, provided the work is properly cited. 